\title{
Remote Presentations: Making L2 Presentations Less Stressful
}

\author{
Dukhayel Aldukhayel $(\mathbb{D}$ \\ Department of English Language and Translation, College of Arabic Language and Social Studies, Qassim University, \\ Buraidah, Saudi Arabia \\ Correspondence should be addressed to Dukhayel Aldukhayel; dmdkhiel@qu.edu.sa
}

Received 23 December 2021; Accepted 11 January 2022; Published 4 February 2022

Academic Editor: Ehsan Namaziandost

Copyright (c) 2022 Dukhayel Aldukhayel. This is an open access article distributed under the Creative Commons Attribution License, which permits unrestricted use, distribution, and reproduction in any medium, provided the original work is properly cited.

\begin{abstract}
This explanatory-sequential mixed-method study was conducted to find out if the affordances of computer-mediated communication (CMC) environments help alleviate L2 public speaking anxiety when giving presentations remotely. Participants were 57 young adult EFL Arabic-speaking learners enrolled in an intermediate listening/speaking class in a preparatory 1 year program at a Saudi public university. Data were collected towards the end of the spring 2021 semester, and the study was conducted in a fully remote learning environment. Two speaking anxiety scales were administered: the Public Speaking Class Anxiety Scale (PSCAS), which measures in-person presentation anxiety, and the Remote Presentation Anxiety Scale (RPAS), an adapted version of PSCAS measuring remote presentation anxiety created and validated by this study. Online follow-up semistructured interviews were then conducted with 10 participants to explain and contextualize the results from the scales. Results of the PSCAS and RPAS analyses indicate that students had medium anxiety for in-person presentations, whereas they experienced low anxiety levels during remote presentations (RPs). Qualitative analyses of the interviews revealed that students preferred RPs over in-person presentations mainly due to its lower anxiety environment. Participants underscored several sociopsychological benefits of presenting remotely such as less stress, less confusion, high self-confidence, comfort, calmness, and relaxation. Implications for research and language teaching are discussed.
\end{abstract}

\section{Introduction}

When schools and universities began teaching fully online in 2020 due to COVID-19, teachers and students found themselves at home teaching and learning using different learning management systems and online platforms (e.g., Blackboard, Zoom, etc.). Such platforms enable teachers to set up virtual classes equipped with many technological tools and techniques that are good alternatives to the physical classroom. Teachers, for example, are able to write or draw on virtual boards for students, and students, on the other hand, can respond to quizzes and tests and do exercises using their digital devices. This method of learning is also referred to as "e-learning," where the students and teachers interact with each other remotely using their digital devices. E-learning provides the students with a lot of opportunities and benefits such as convenience, flexibility, time-saving, teamwork, as well as opportunities to collaborate with others across physical boundaries [1-3]. It also allows students to have more control over their learning activities and to make decisions about their routine classwork in terms of space, pace, depth, breadth, and time management [4].

In the specific context of second language learning, several benefits of computer-assisted language learning (CALL) have been pointed out. However, the focus in this study will be on reducing L2 speaking anxiety. Speaking is considered to be one of the most relative anxiety-provoking dimensions of language learning [5], and anxiety may cause L2 learners who are not yet proficient to perform poorly [6]. Computer-mediated communication (CMC) research has shown that $\mathrm{CMC}$ environments play important roles in reducing L2 speaking anxiety (e.g., $[7,8]$ ). Because CMC helps reduce social-context clues (e.g., gender, race, status, etc.) as well as nonverbal cues (e.g., facial expressions, body language, etc.), shy or less confident language learners feel safe and more relaxed in CMC sessions $[9,10]$. For instance, 
virtual language learning environments such as Second Life have been found to be a more relaxed and carefree setting for learners to interact with each other, diminishing L2 speaking anxiety levels and improving the speaking performance of EFL learners (e.g., [11]). Similarly, public presentation, regarded as a specific subtype of public speaking, is another source of anxiety in learning a second language [12]. Public speaking is scary enough, but giving a presentation in the target language in front of peers can be even more intimidating. L2 learners often have to prepare a talk on a topic, make PowerPoint slides, and give presentations in the classroom in front of their classmates, especially for L2 speaking classes. With online learning, students have to give remote presentations (RPs) to a virtual roomful of classmates as an alternative to the in-person, in-classroom presentations.

Exploring the potential of RPs to alleviate such anxiety and stress is paramount, especially given that technology and virtual classes could bring some unexpected benefits. This is the main goal of the study in that it investigates whether technology is effective at alleviating or diminishing public speaking anxiety (PSA). Since current research on the effects of CMC on reducing L2 speaking anxiety has been limited to situations when technology was used to teach speaking, this study aims to contribute to the current knowledge by extending the research to include speaking testing and evaluation such as giving oral presentations. As such, an explanatory-sequential mixed-method study was conducted with EFL Arabic-speaking learners who provided their responses to two different speaking anxiety scales and participated in online interviews around the time of giving RPs through virtual classes using the Blackboard learning management platform.

\subsection{Literature Review}

1.1.1. Second Language Anxiety. Considering its massive negative impact on L2 learning, anxiety has caught the attention of L2 researchers since the early 1970s (e.g., [5, 13-17]). Horwitz et al.'s [5] study, in particular, had a major influence on L2 anxiety research that resulted in the corresponding development of the Foreign Language Classroom Anxiety Scale (FLCAS). Horwitz et al. viewed L2 anxiety as "distinct complex self-perceptions, beliefs, feelings, and behaviors related to classroom language learning arising from the uniqueness of the learning process" (p. 128). L2 anxiety has been conceptualized by other researchers (e.g., $[18,19])$ as a complicated psychological phenomenon in which the learners experiences feelings of tension and apprehension caused by specific L2 language situations (e.g., speaking, listening, etc.) or the worry, negative beliefs, and emotions when learning or using the L2.

Many of the earlier studies on L2 anxiety investigated how this construct affected language learning achievement. For instance, Steinberg and Horwitz [20] examined the impact of induced anxiety on ESL Spanish learners' L2 oral production of stimulus pictures. They found that the content of L2 speech differed depending on whether they were describing the pictures under anxiety-inducing or relaxed conditions with learners producing significantly less personal and interpretive speech in the anxiety conditions. In another study, Gardner and MacIntyre [21] studied the affective variables among English-speaking learners of French in cloze and composition tasks and an objective test. They concluded that classroom and L2 use anxiety had a significant negative relationship with several outcome measures of L2 French performance. In the same vein, MacIntyre and Gardner [18] found that L2 anxiety was associated with poor performance at the input, process, and output stages of L2 learning, with the processing and output stages having the strongest relationships. They suggested that L2 anxiety appeared to interfere with both the development of overall language achievement and the ability to meaningfully produce the L2.

L2 anxiety empirical research has identified various characteristics of anxious learners. For instance, Burden [22] noted that anxious students are often concerned about the impressions of their classmates and often choose to withdraw from classroom learning activities in which they do not feel comfortable. Burden also assumed that most anxious learners do not have a strong belief in their L2 performance, causing them to develop negative expectations about themselves and eventually avoid all helpful opportunities to enhance their communication skills. Furthermore, some empirical studies (e.g., $[13,23]$ ) found that anxious learners generally lack the willingness to participate in classroom learning activities and their overall performance is worse than that of their nonanxious peers. Significant language anxiety can have significant consequences on EFL learners' performance, including situations in which learners purposefully delay school work, avoid speaking in class, or, at worst, change their majors to escape foreign language study [24]. As such, Horwitz et al. [5] called for practical reforms at all levels of L2 teaching by recognizing, coping with, and eventually overcoming L2 anxiety that can have negative impacts on L2 learning experiences.

There are various types of anxiety including "trait anxiety," which concerns personality and is considered as a permanent trait [17]; "state anxiety" (also "temporary anxiety"), which exists in reaction to a specific situation at a particular time; and "situation-specific anxiety," which is defined as apprehension about specific events and situations [25]. L2 anxiety involves a complex set of behaviors, thoughts, anticipations, and feelings influenced by the language learning process [5], and it is often experienced by less proficient learners during L2 use [21]. Past research concluded that L2 anxiety is different from and independent of personality trait anxiety and state anxiety. MacIntyre and Gardner [23] concluded that the anxiety that specifically deteriorates L2 vocabulary acquisition and production is different from anxiety in general. Dörnyei [14] also noted that L2 anxiety is a uniquely L2-related variable and is not transferred from other domains such as test anxiety or communication apprehension.

L2 anxiety falls under the category of situation-specific anxiety. L2 anxiety has been further classified into three types. First is communication apprehension, described by Horwitz et al. [5] as "a type of shyness characterized by fear of or 
anxiety about communicating with people" (p. 127). The second is test anxiety, which "refers to a type of performance anxiety stemming from a fear of failure" ([5], p. 127). Last is fear of negative evaluation, referring to the "apprehension about others' evaluations, avoidance of evaluative situations, and the expectation that others would evaluate oneself negatively" ([5], p. 128). The focus of this study is communication apprehension that includes L2 speaking anxiety and L2 public speaking anxiety.

1.2. L2 Speaking Anxiety. Learning an L2 in an effective way requires learners to actively speak the target language; however, speaking in the L2 can provoke a great deal of anxiety [26, 27]. A considerable amount of research has regarded speaking as the most anxiety-provoking language skill [19] and concluded that anxiety is an effective factor that negatively affects speaking performance $[14,28,29]$. L2 speaking anxiety is regarded as the most salient form of L2 anxiety in L2 learning. Speaking anxiety, also known as communication apprehension [5], refers to the situation in which an individual experiences worry, uneasiness, and panic when expressing themselves orally. Mak [30] suggested that oral tasks are regarded as the main reason for anxiety in L2 classrooms. Liu and Jackson [31] attributed speaking anxiety to personal and social problems including low self-esteem, weak communicative competence, and poor social engagement. Speaking anxiety is a major obstacle in the way of L2 communication as it deeply affects the quality of L2 learners' oral performance. In addition, the specific characteristics of speaking cause some L2 learners to feel anxious, uneasy, and stressed-out [5, 32], and because speech cannot be produced without physical involvement, it might cause unpleasant physical outcomes such as nausea, sweating, weak knees, and so forth [33]. Communication apprehension is suggested to be the result of difficulties faced by L2 learners when speaking in L2 classrooms [32]. Speaking is a stressful skill for L2 learners because it is entirely dependent on one's individual cognitive abilities [5] and learners often lose control of cognitive performance in the process of L2 speaking [34].

1.3. L2 Public Speaking Anxiety. Public speaking is scary enough, but giving a presentation in the target language can be even more intimidating. Speaking in front of peers is another source of anxiety in learning a foreign language [12]. Public speaking anxiety (PSA) is a serious psychological problem that causes feelings of intense fear, dread, or unease in current or anticipated speaking situations [35]. Although PSA is commonly considered as a distinct subtype of social anxiety, there are some differences and similarities between people with general social phobias and those with public speaking phobias. For instance, recent research indicates that individuals with PSA endured more difficult times with cardiovascular arousal during challenges [36]. According to Pertaub et al. [37], most individuals who have PSA also have a fear that other people would criticize or humiliate them even when they know that this fear is baseless.
Individuals with PSA feel uncomfortable in social interactions and become more self-conscious, causing elevated heart rate and high blood pressure particularly when they have to speak in front of the public [38]. Indeed, PSA causes anxious people to experience several physiological, cognitive, and behavioral changes when performing or even only anticipating the situation. According to research in physiology (e.g., [39]), the most common physiological changes include heart rate, blood pressure, sweating, and muscle tension once the autonomic nervous system is activated. Moreover, Vîslă et al. [40] have suggested that people who are anxious about public speaking generate some beliefs that in turn generate dysfunctional feelings and behaviors. Those beliefs can be descriptions (e.g., "The room is full of people"), inferences (e.g., "They will laugh at me"), or evaluations/ appraisals (e.g., "They must not laugh at me and it is awful if they do"). Typically, those individuals prefer to skip or avoid the anxiety-eliciting social events whenever possible [37].

1.4. L2 Speaking Anxiety and Technology. Computers and technology have, in many ways, played a considerable role in facilitating second language learning and teaching processes. To begin with, it has facilitated communication and interaction in the target language, as it provides synchronous and asynchronous communication modes and interaction opportunities [41]. CMC is not only a type of human communication facilitated by computers and technology [42] but also provides a friendly and more relaxed environment for L2 learners, especially for the shy, anxious, or less confident individuals thanks to its affordances in reducing socialcontext cues and nonverbal cues $[9,10]$. More importantly, in contrast to traditional classroom environments, CMC allows more time for learners to prepare for their speech and express their thoughts at their own pace and in their own space so that they do not have to compete with their classroom peers for the teacher's attention [10]. In essence, CMC delays or prevents peer judgment and teacher expectations, which can, in turn, reduce anxiety and boost confidence when speaking [43].

Research shows that CMC can reduce anxiety in L2 learning. Arnold [44], for instance, is one of the earlier experimental studies that examined the effect of synchronous and asynchronous CMC on communication apprehension. In this study, a group of EFL learners were assigned to experimental and control groups. Data were collected from students' self-reports and pre- and post-test communication apprehension scores. The study concluded that learners experienced only low levels of communication apprehension during CMC sessions. There are studies that were indirectly related to L2 anxiety that examined the effects of voice boards on speaking skills. For example, Hsu et al. [45] collected qualitative data (i.e., interview and analysis of blogs) regarding 22 EFL learners' perceptions of voice boards. They found that the students who were enrolled in an advanced English conversation course felt comfortable with the use of voice boards. In another study, Sun [46] explored EFL learners' perceptions of voice boards and found voice board activities were also helpful in reducing L2 anxiety. 
Results of studies on the effects of virtual language learning environments such as Second Life also concluded that the level of L2 anxiety decreased. For instance, Wehner et al. [47] utilized Second Life with American students of Spanish and suggested that virtual worlds might lower L2 anxiety and increase L2 motivation. In another study, Wang and Shao [48] also found that Second Life was an effective way of improving their EFL Chinese learners' speaking skills and reducing L2 speaking anxiety. Balcikanli [49] reported on the Second Life experiences of American learners of Turkish as a Foreign Language and of Turkish learners of EFL. Data collected from interviews demonstrated that both groups of students regarded Second Life as less anxietyprovoking than regular face-to-face interactions because of its anxiety-lowering nature. Liou [50] is another study in which Second Life was infused into a CALL course for 25 college EFL Taiwanese students. At the end of the study, most students agreed that Second Life reduced their English learning anxiety levels. Bashori et al. [51] used two automatic speech recognition-based learning websites to investigate L2 speaking anxiety among EFL Indonesian learners. Participants evaluated the learning websites positively, believed that web-based language learning could alleviate their speaking anxiety, and reported less anxiety when speaking English. More recently, York et al. [52] compared the effect of three modes of synchronous CMC on learners' L2 speaking anxiety: oral SCMC, video SCMC, and virtual reality. The findings indicated all three modes were effective in reducing learners' anxiety.

This concise review of CMC and related research findings illustrates that L2 speaking anxiety can be lowered by the use of different CMC tools. Nevertheless, the relevant literature highlights that $\mathrm{CMC}$ has yet to be explored to any great extent in specific relation to reducing PSA. Current research has been limited to the effects of CMC on reducing L2 speaking anxiety when technology is used for teaching speaking and has yet to be extended to speaking testing and evaluation such as giving presentations. Similarly, it can be seen that there is a notable dearth of research into the use of the Blackboard learning management platform for delivering RPs through virtual classes and how that can affect L2 speaking anxiety. As such, the research questions for this study were as follows:

(1) How do the speaking anxiety levels experienced by EFL learners in RPs differ, if at all, from anxiety levels during in-person, in-classroom presentations?

(2) If a difference is present, what is the relationship between RPs and the difference in anxiety levels?

\section{Methodology}

2.1. Study Design. An explanatory-sequential mixedmethods design [53] was used in this study. This design is typically characterized by an initial quantitative data phase, which is then followed by a qualitative collection phase. The two data sets are then integrated during the interpretation phase. Findings from the qualitative component are used to explain and contextualize the results from the quantitative component. The sources of the quantitative data were two speaking anxiety scales administered to all participants $(n=57)$ in the study. The two scales were the Public Speaking Class Anxiety Scale (PSCAS; [54]), which measures inperson presentation anxiety, and the Remote Presentation Anxiety Scale (RPAS), which is an adapted version of PSCAS measuring remote presentation anxiety created and validated by this study. The qualitative data were collected from semistructured interviews with ten students based on availability and willingness to participate. The interviews were intended to provide insight into the scales' findings and were conducted subsequent to the analysis of the data (sequentially). Thus, the use of an explanatory-sequential mixed-methods design allowed for the establishment of the participants' speaking anxiety levels through the use of the two scales before collecting insights explaining and contextualizing the anxiety levels revealed by the scales.

\section{Research Settings}

The study was conducted in a preparatory 1 year program at a Saudi public university towards the end of the spring 2021 semester. The program is a pre-university intensive English program run by the university designed for students who are interested in going to the health and engineering colleges where English is the medium of instruction. The program focuses on the four basic skills in reading, writing, speaking, and listening and other scientific subjects such as physics, math, and computer science that are also taught in English. Students in the program study 30 hours per week (half of which are for English language learning) and mostly finish the program in two semesters. In semester 1, beginning/ intermediate English classes are offered, whereas intermediate/advanced English classes are offered in semester 2.

\section{Participants}

The participants $(n=57)$ were Arabic-speaking EFL learners $\left(M_{\text {age }}=18.10\right.$ years, $\left.\mathrm{SD}=0.47\right)$ and were drawn from three intact intermediate listening/speaking classes. Students had upper-intermediate levels of overall English proficiency as well as upper-intermediate English-speaking skills. Participants in the program typically had studied English for a minimum of seven years before attending the program. Most of their exposure to English was achieved through formal education in public intermediate and high schools. Very few had travelled abroad to study English in English-speaking countries. Also, very few students spoke English outside the university. Most of the students' speaking of English was limited to the duration of the English classes or with teachers inside the program.

\section{Listening/Speaking Class Description}

In semester 2, the listening/speaking class was an intermediate-/advanced-level class offered twice a week (1 h $40 \mathrm{~min} / \mathrm{session)}$ for a 14 -week semester. This semester-long class has been moved completely online since spring 2020. Blackboard is the official online 
learning management platform used by the university. The textbook used for the class was Q: Skills for Success Special Edition Listening and Speaking Level 3 [55]. The language level of the textbook is B1 of the Common European Framework of Reference for Languages. The textbook is designed on an interactive learner-centered communicative approach, so teaching in the class focuses on how to communicate effectively in a cultural context and encourages the simultaneous use of a variety of integrated skills rather than practicing each individual skill one at a time.

The public presentation assignment was a part of the speaking skill assessment for the listening/speaking class. During the semester, students are required to do two presentations: one for the mid-semester evaluation and one for the end of the semester. Regarding presentation instructions, students were informed to create PowerPoint slides on a topic of their own choice and present for about $5 \mathrm{~min}$. Students were assessed on four aspects: grammar, pronunciation, fluency, and vocabulary. The full possible mark was 3 . The speaking evaluation was considered a low-stakes assessment, so the assessment aspect should not cause anxiety in and of itself. When giving presentations in a remote learning environment, students can either do a live presentation in front of the class on platforms (synchronous) or pre-record their presentation for instructors and peers to view later (asynchronous). In this study, students were required to do presentations synchronously via Blackboard in order to closely simulate the in-person, in-classroom presentations. Students were allowed to do audio-video presentations or audio-only presentations. However, all students did audio-only presentations while displaying their PowerPoint slides.

\section{Instruments}

6.1. Public Speaking Class Anxiety Scale (PSCAS). Before measuring anxiety in RPs, it was necessary to initially establish whether students have in-person presentation anxiety. Thus, the Public Speaking Class Anxiety Scale (PSCAS; see Appendix A) developed by Yaikhong and Usaha [54] was used to measure participants' public speaking anxiety in class. Items in the PSCAS were adopted from some wellknown scales including Horwitz et al.'s [5] Foreign Language Classroom Anxiety Scale (FLCAS), McCroskey's [56] Personal Report of Communication Apprehension (PRCA-24), and Personal Report of Public Speaking Anxiety (PRPSA34), and Clevenger and Halvorson's [57] Speaker Anxiety Scale (SAS). The PSCAS comprises 17 items, each of which was answered on a 5-point Likert scale, ranging from "strongly agree" to "strongly disagree." PSCAS yielded an internal consistency of 0.85 using Cronbach's alpha coefficient when administered to participants.

6.2. Remote Presentation Anxiety Scale (RPAS). A scale was developed to measure participants' anxiety caused by RPs named the Remote Presentation Anxiety Scale (RPAS; see Appendix B). Items in the RPAS were adopted from the PSCAS (which was already developed based on some previous scales). The RPAS comprises eight items, each of which was answered on a five-point Likert scale, ranging from "strongly agree" to "strongly disagree." The RPAS yielded an internal consistency of 0.83 using Cronbach's alpha coefficient. The results of the RPAS would be then compared to the results of the PSCAS in order to find any significant differences in the anxiety levels between inperson presentations and remote presentations.

6.3. Semistructured Interviews. Besides the two speaking anxiety scales, semistructured interviews with 10 students who voluntarily participated were conducted online. The interviews were conducted after the analysis procedures for the scales were completed and once the results of the scales were achieved. With the anxiety levels being established and known, the researcher created questions for the interviews based on the scales' findings since the purpose of the interviews was to explain and contextualize the speaking anxiety levels revealed by the scales. All interviews lasted for about 20 minutes and were conducted over 2 days. The interviews were recorded on the researcher's laptop after the students' consent was given and then were transcribed. Questions posed during the interviews can be found in Appendix C.

6.4. Data Collection Procedures. The study took place towards the end of the spring semester because it targeted the second presentation. The assumption was that students have developed clear perceptions of RPs after their second experience. Students in the three classes delivered their RPs in a single week (week 12, according to the syllabus) in two lectures (every $100 \mathrm{~min}$ ). In each class, students were randomly divided into half, and each half of the students presented in one lecture. Prior to the RP week (i.e., in week 11), the PSCAS was administered to establish students' inperson presentation anxiety. After finishing their RPs, students were informed to go to the RPAS and provide their responses. Both scales were created on Google Forms, and the links to the scales were sent to all students via e-mail. In the following week (week 13), after scales were analyzed, interviews were conducted at the students' convenience.

\section{Data Analysis}

7.1. PSCAS. The total score of the PSCAS reveals a respondent's general tendency to feel nervous and anxious about public in-person speaking. The higher the score, the higher anxiety the respondent has. To analyze levels of anxiety using the PSCAS, the suggested guidelines by Yaikhong and Usaha [54] and Liu and Jackson [31] are to multiply the number of the items in the scale (17) with the highest possible score for each item (5) and then subtract the total items of the scale (17) from the total multiplied score (85). Thus, the PSCAS total multiplied score of 85 was then subtracted by 17 ; scores higher than 68 were categorized as high anxiety, between 51 and 68 as medium anxiety, and lower than 51 as low anxiety. In terms of anxiety levels based on the mean, the mean scores that fall within the interval of 3 
to 4 were categorized as medium anxiety level, below 3 as low anxiety level, and above 4 as high anxiety level. Because the PSCAS primarily was designed to measure individuals' anxiety about speaking in person, items that expressed confidence in public speaking had the values assigned to their alternatives reversed. Namely, for items \#4, 8, 10, and 12 , the response "strongly disagree" received a score of 5 instead of 1; the response "strongly agree" was given a value of 1 instead of 5; and so on (see Appendix A).

7.2. RPAS. Similarly, the total score of the RPAS reveals a respondent's general tendency not to feel calm and relaxed in RPs. The higher the score, the more anxious the respondent is. The RPAS total multiplied score was 40 , which was then subtracted by 8 total items; scores higher than 32 were categorized as high anxiety, between 24 and 32 as medium anxiety, and less than 24 as low anxiety. In terms of anxiety levels based on mean, it was similarly determined that mean scores that fall within the interval of 1 to 4 were categorized as medium anxiety level, below 3 as low anxiety level, and above 4 as high anxiety level. The RPAS primarily was designed to measure individuals' RP anxiety, so items that expressed confidence in RP had the values assigned to their alternatives reversed. Namely, for items \#3, 5, and 8, the response "strongly disagree" received a score of 5 instead of 1 ; the response "strongly agree" was given a value of 1 instead of 5; and so on (see Appendix B).

\section{Semistructured Interviews}

A conceptual content analysis [58] was performed on the semistructured interview transcripts using NVIVO version 12. Conceptual analysis (also known as thematic analysis) refers to the process in which a text is scrutinized to check the existence and frequency of a concept or theme. In this method, instead of counting the frequency of word usage, this approach attempts to find similar cognitions under the same concept [59].

\section{Results}

Following the explanatory-sequential mixed-methods design, the data collection and data analysis were first performed on the quantitative data sets (PSCAS and RPAS) and then on the qualitative data (semistructured interviews). The quantitative analysis included pooling answers to the 17 items of the PSCAS and the 8 items of the RPAS for each learner $(n=57)$. For each student, their anxiety level was investigated both based on the total score and based on the mean on each scale. After gathering the mean ratings, IBM SPSS 24 software was used to calculate Cronbach's alpha. An independent samples $t$-test was carried out to compare the means for all students on both scales (because each scale has a different total score, comparing the total scores was not possible). The qualitative analysis of the semistructured interviews first included verbatim transcriptions of the recordings of the 10 learners. They were then coded and organized into the main theme, which referred to comfort levels in speaking the L2. Results from both the PSCAS and RPAS and those from the semistructured interviews are reported below.
9.1. PSCAS and RPAS. The students' answers to the 17 items of PSCAS and the 8 items of the RPAS were examined. For each student, on each scale (i.e., PSCAS and RPAS), the anxiety level was investigated both based on the total score and based on mean. To assess internal consistency, Cronbach's alpha coefficients were computed for all responses, with scores of 0.85 for the PSCAS and 0.83 for the RPAS, indicating an acceptable level of internal reliability. Regarding the PSCAS, the mean of the total multiplied scores for all students was $61.5(\mathrm{SD}=0.32)$, and the mean of the students' means was $3.2(\mathrm{SD}=0.61)$, indicating a medium anxiety level. With regard to the RPAS, the mean of the total multiplied scores was $25.1(\mathrm{SD}=0.19)$, and the mean of the means was $2.6(\mathrm{SD}=0.35)$, indicating a low anxiety level. An independent samples $t$-test was carried out to compare the means on the 2 scales. A significant difference was found between the in-person presentation anxiety level $(M=3.2$, $\mathrm{SD}=0.61)$ and the remote presentation anxiety level $(M=2.6, \mathrm{SD}=0.35) ; t(55)=-2.08, p=0.03$. The effect size as measured by $d$ was 0.69 , which is considered a medium effect size, according to Plonsky and Oswald [60].

\section{Semistructured Interviews}

Table 1 presents the results of the conceptual content analysis that was conducted on the participants' semistructured interview transcripts. The results are presented from positive to negative with more frequent themes displayed first. They provide the reader with a quick general summary of the semistructured interview findings. Overall, the participants more frequently talked positively about RP than they talked about the negative aspects.

\section{Discussion}

This study sought to investigate (a) the efficacy of technology and CMC at alleviatingor eliminating PSA and (b) the potential of RPs on EFL Arabic-speaking learners' L2 speaking anxiety using the blackboard learning management platform. The first research question was: "How do the speaking anxiety levels experienced by EFL learners in RPs differ, if at all, from anxiety levels during in-person, inclassroom presentations?" In pursuing the answer to this question, an independent samples $t$-test was carried out. The results revealed indicate that the students' L2 speaking anxiety levels during RPs were significantly lower than those during in-person presentations. As the PSCAS results show, participants reported medium levels of anxiety caused by inperson public presentations, whereas results of the RPAS indicate that the same participants only experienced low anxiety levels during RPs. Data from the semistructured interviews support these findings and suggest that delivering RPs through Blackboard was a less anxiety-provoking platform. Nine participants specifically expressed positivity about RPs and delivering presentations through Blackboard. Students described positive feelings and emotions about RPs before, during, and after presenting; they described the experience of presenting remotely as fun, comfortable, and relaxed. These results are consistent with the findings of 
TABLE 1: Summary of interview responses about RPs.

\begin{tabular}{lcc}
\hline & Theme and description & Frequency \\
\hline+ & Overall positive perceptions (pleasant experience, good alternative, and fun) & 9 \\
+ & Feelings before the presentation (low anxiety, pressure, and stress) & 7 \\
+ & Feelings during presentation (relaxed and confident) & 7 \\
+ & Feelings after presentation (satisfaction) & 5 \\
$\sim$ & Classmates' perceptions of RPs & 4 \\
$\sim$ & The effectiveness of technology on language quality & \\
- & Absence of body language affected performance and attention & \\
- & Technological issues cause stress (downs in internet speed and distorted audio) & \\
\hline
\end{tabular}

Note.$+=$ Positive comment, $\sim=$ neutral comment, and $-=$ negative comment.

several related studies (e.g., [44-47, 49, 50, 52]), which documented lower communication apprehension when CMC using different tools was integrated into L2 learning. These studies suggest that CMC and technology play a significant role in reducing $\mathrm{L} 2$ speaking anxiety and boosting confidence among L2 learners in that social-context clues and nonverbal cues are reduced in CMC technology $[9,10]$.

The second research question was: "If a difference is present, what is the relationship between RPs and the difference in anxiety levels?" To answer this question, students' responses collected from the interviews were analyzed. Analysis of the interviews indicates that the confidence issue among students appears to be reduced during RPs as they were presenting in the comfort of their homes. It seems to relax them to know that much of the audience are also probably more laid back and relaxed as well. Another possible explanation found by the analysis of the interviews for the high confidence seen during RPs was that students were only available auditorily, so the focus was less on them and more on the technology and the message. Compared to the inperson, in-classroom presentations, physical involvement in RPs is minimized and so is anxiety. The following excerpts are comments made by the students in the interviews:

"The most important personal feature in RPs is the comfort in dress, sitting, and other things ... and of course, the most important feature is the psychological comfort. I think that these features made me more confident when I was presenting than in front of others or in face to face."

"In RPs, I don't need to take care of my appearance ... unlike if I present in front of my classmates. Also, RPs ease students who get nervous when people are looking at them, so they can give a better presentation."

"Presenting from a distance is characterized by calm and serenity. A student can deliver the presentation with ease, and completely without any anxiety or tension that often exists when presenting than in front of students."

"I believe the only difference between presenting remotely and in-person presentation is in the psychological aspect ...., i.e., the person is more comfortable and less tense, and this naturally leads to many positive results."

As a note that should be highlighted regarding our results, all students chose to deliver their RPs auditorily with the cameras turned off. That could have contributed to the significantly lower anxiety levels, and we do not know if these low anxiety levels could be maintained if students were required to do audio-video presentations and to turn cameras on. Of course, research (e.g., [52]) suggests that CMC reduces L2 anxiety in any mode (i.e., video or audio); however, there is another line of research (e.g., [61]) that found that anxiety was not reduced by audio-based CMC and that only text-based $\mathrm{CMC}$ was effective at reducing anxiety.

Finally, as with any technology tool, four participants expressed some aspects of negativity about RPs. Two participants provided comments suggesting that the absence of body language such as gestures and facial expressions in the audio-only RPs was a drawback; one participant said that the fact that he could not use body language affected his performance and enthusiasm; and another one said that he could not pay enough attention to classmates' RPs because he could not see the manner of how they were presenting. Two other students mentioned that technological issues made them feel stressed or less interested in classmates' RPs; one student said that he felt stressed because of the unexpected random downs in internet speed at home; and another one said he lost interest in attending classmates' RPs because either the audio was distorted or he heard an echo when they were speaking.

\section{Limitations}

There are several limitations in the present study; thus, our results should be interpreted with caution. First, students relied on memory when responding to the PSCAS rather than on a fresh experience as was the case for the RPAS. The PSCAS data might be less accurate than those of the RPAS, although we believe that they are realistic and reflective of the L2 in-person, in-classroom presentation circumstances. Another limitation concerns the fact that students were allowed to do audio-only RPs and were not required to turn cameras on to do audio-video presentations that closely simulate the in-person, in-classroom presentations. CMC research would benefit from studies that look at the anxiety levels when doing audio-video RPs to see if similar results are found. Lastly, all participants had similar levels of English proficiency (an upper-intermediate level). It might be useful for future research to include different levels of English proficiency, which can help paint a clearer picture of the affordances of CMC and RPs in decreasing or eliminating PSA. 


\section{Implications}

These findings have implications for L2 speaking teaching and assessment. First, when giving a presentation is a course learning requirement in the syllabus, making options and solutions available to anxious students is pedagogically important. In this study, delivering RPs was the only available option for giving presentations due to the fully online instruction and was different from the typical instructions for presentations in the listening/speaking class syllabus. Students were further allowed to choose between audio-video presentations or audio-only presentations. This step appeared to positively impact students' presentation performance in that it helped reduce speaking anxiety. L2 speaking instructors might consider RPs when in-person presentations cause confidence issues, and they should make all options available for creating a friendly and more relaxed learning environment. In this way, students feel less stressed, confident, comfortable, and relaxed in their L2 learning journey.

\section{Conclusion}

This study suggests that CMC has a positive effect on the speaking and presentation performance of EFL learners when they are allowed to deliver presentations remotely. Comparison of students' L2 speaking anxiety levels during RPs and during in-person presentations showed that CMC and technology significantly and positively impacted students' communication apprehension. Specifically, compared to feelings of tension and apprehension caused by in-person, in-classroom presentations, feelings during RPs were much more positive. While this study only looked at the effectiveness of CMC and virtual classrooms for anxiety reduction in speaking testing settings, it does provide support for using virtual classrooms for anxiety reduction in the teaching of speaking as well.[62].

\section{Appendix}

\section{A. Public Speaking Class Anxiety Scale (PSCAS)}

(1) I never feel quite sure of myself while I am speaking English.

Strongly agree | Agree | Neither agree nor disagree | Disagree | Strongly disagree

(2) I start to panic when I have to speak English without preparation in advance.

Strongly agree | Agree | Neither agree nor disagree | Disagree | Strongly disagree

(3) In a speaking class, I can get so nervous I forget things I know.

Strongly agree | Agree | Neither agree nor disagree | Disagree | Strongly disagree

(4) I feel confident while I am speaking English.

Strongly agree | Agree | Neither agree nor disagree | Disagree | Strongly disagree

(5) I get nervous and confused when I am speaking English.
Strongly agree | Agree | Neither agree nor disagree | Disagree | Strongly disagree

(6) I am afraid that other students will laugh at me while I am speaking English.

Strongly agree | Agree | Neither agree nor disagree | Disagree | Strongly disagree

(7) I get nervous when the English teacher asks me to speak English that I have prepared in advance.

Strongly agree | Agree | Neither agree nor disagree | Disagree | Strongly disagree

(8) I have no fear of speaking English.

Strongly agree | Agree | Neither agree nor disagree | Disagree | Strongly disagree

(9) I can feel my heart pounding when I am going to be called on.

Strongly agree | Agree | Neither agree nor disagree | Disagree | Strongly disagree

(10) I feel relaxed while I am speaking English.

Strongly agree | Agree | Neither agree nor disagree | Disagree | Strongly disagree

(11) It embarrasses me to volunteer to go out first to speak English.

Strongly agree | Agree | Neither agree nor disagree | Disagree | Strongly disagree

(12) I face the prospect of speaking English with confidence.

Strongly agree | Agree | Neither agree nor disagree | Disagree | Strongly disagree

(13) Certain parts of my body feel very tense and rigid while I am speaking English.

Strongly agree | Agree | Neither agree nor disagree | Disagree | Strongly disagree

(14) I feel anxious while I am waiting to speak English. Strongly agree | Agree | Neither agree nor disagree | Disagree | Strongly disagree

(15) I dislike using my voice and body expressively while I am speaking English.

Strongly agree | Agree | Neither agree nor disagree | Disagree | Strongly disagree

(16) I have trouble coordinating my movements while I am speaking English.

Strongly agree | Agree | Neither agree nor disagree | Disagree | Strongly disagree

(17) Even if I am very well prepared, I feel anxious about speaking English.

Strongly agree | Agree | Neither agree nor disagree | Disagree | Strongly disagree

\section{B. Remote Presentation Anxiety Scale (RPAS)}

(1) I did not feel quite sure of myself when I delivered my remote presentation. 
Strongly agree | Agree | Neither agree nor disagree | Disagree | Strongly disagree

(2) I started to panic when I had to start my remote presentation.

Strongly agree | Agree | Neither agree nor disagree | Disagree | Strongly disagree

(3) I felt confident when I delivered my remote presentation.

Strongly agree | Agree | Neither agree nor disagree | Disagree | Strongly disagree

(4) I could feel my heart pounding when I had to start my remote presentation.

Strongly agree | Agree | Neither agree nor disagree | Disagree | Strongly disagree

(5) I did not feel pressure to prepare for my remote presentation.

Strongly agree | Agree | Neither agree nor disagree | Disagree | Strongly disagree

(6) I felt very self-conscious about delivering my remote presentation.

Strongly agree | Agree | Neither agree nor disagree | Disagree | Strongly disagree

(7) I got nervous and confused when I was delivering my remote presentation.

Strongly agree | Agree | Neither agree nor disagree | Disagree | Strongly disagree

(8) I was comfortable when I was delivering my remote presentation.

Strongly agree | Agree | Neither agree nor disagree | Disagree | Strongly disagree

\section{Semistructured Interviews Questions}

(1) What did you think of presenting remotely? Name the advantages and disadvantages.

(2) How did you feel when you found out you will have to present remotely?

(3) Did your opinion of remote presentations change after you finished? For example, maybe you disliked it at the beginning but liked it afterwards, or vice versa?

(4) What did the other students in the class think about presenting remotely?

(5) Do you think presenting remotely had an effect on your performance? What type of effect?

(6) Do you think it is a good idea to have all presentations done remotely after COVID-19?

(7) Would you like to have the option to present remotely in the future?

(8) Do you have any other comments about remote presentations?

\section{Data Availability}

The data used to support the findings of this study are included within the article.

\section{Conflicts of Interest}

The author declares that there are no conflicts of interest.

\section{References}

[1] J. F. Chizmar and M. S. Walbert, "Web-based learning environments guided by principles of good teaching practice," The Journal of Economic Education, vol. 30, no. 3, pp. 248-259, 1999.

[2] M.-L. Hung, C. Chou, C.-H. Chen, and Z.-Y. Own, "Learner readiness for online learning: scale development and student perceptions," Computers \& Education, vol. 55, no. 3, pp. 1080-1090, 2010.

[3] D. M. Poole, "Student participation in a discussion-oriented online course," Journal of Research on Computing in Education, vol. 33, no. 2, pp. 162-177, 2000.

[4] M. Stansfield, E. McLellan, and T. Connolly, "Enhancing student performance in online learning and traditional faceto-face class delivery," Journal of Information Technology Education: Research, vol. 3, no. 1, pp. 173-188, 2004.

[5] E. K. Horwitz, M. B. Horwitz, and J. Cope, "Foreign language classroom anxiety," The Modern Language Journal, vol. 70, no. 2, pp. 125-132, 1986.

[6] A. Galante, "Drama for L2 speaking and language anxiety: evidence from Brazilian EFL learners," RELC Journal, vol. 49, no. 3, pp. 273-289, 2018.

[7] D. M. Chun, "Using computer networking to facilitate the acquisition of interactive competence," System, vol. 22, no. 1, pp. 17-31, 1994.

[8] R. G. Kern, "Restructuring classroom interaction with networked computers: effects on quantity and characteristics of language production," The Modern Language Journal, vol. 79, no. 4, pp. 457-476, 1995.

[9] E. Hanson-Smith, "Computer-assisted language learning," in The Cambridge Guide to Teaching English to Speakers of Other Languages, R. Carter and D. Nunan, Eds., Cambridge University Press, Cambridge, UK, 2001.

[10] L. Sproull and S. Kiesler, "Computers, networks and work," Scientific American, vol. 265, no. 3, pp. 116-123, 1991.

[11] S. Güzel and S. Aydin, "The effect of second Life as a virtual language learning environment on speaking anxiety," in Assessing the Effectiveness of Virtual Technologies in Foreign and Second Language Instruction, M. Kruk, Ed., pp. 115-146, IGI Global, Pennsylvania, PA, USA, 2019.

[12] A. S. Koch and T. D. Terrell, "Affective reactions of foreign language students to natural approach activities and teaching techniques," in Language Anxiety: From Theory and Research to Classroom Implications, E. K. Horwitz and D. J. Young, Eds., pp. 109-126, Prentice-Hall, Hoboke, NJ, USA, 1991.

[13] Y. Aida, "Examination of Horwitz, Horwitz, and cope's construct of foreign language anxiety: the case of students of Japanese," The Modern Language Journal, vol. 78, no. 2, pp. 155-168, 1994.

[14] Z. Dörnyei, The Psychology of the Language Learner: Individual Differences in Second Language Acquisition, Lawrence Erlbaum, Mahwah, NJ, USA, 2005. 
[15] E. K. Horwitz, "Preliminary evidence for the reliability and validity of a foreign language anxiety scale," Tesol Quarterly, vol. 20, no. 3, pp. 559-562, 1986.

[16] E. Horwitz and D. Young, Language Anxiety: From Theory and Research to Classroom Implications, Prentice-Hall, Hoboken, NJ, USA, 1991.

[17] T. Scovel, "The effect of affect on foreign language learning: a review of the anxiety research," Language Learning, vol. 28, no. 1, pp. 129-142, 1978.

[18] P. D. MacIntyre and R. C. Gardner, "The subtle effects of language anxiety on cognitive processing in the second language," Language Learning, vol. 44, no. 2, pp. 283-305, 1994.

[19] D. J. Young, "language anxiety from the foreign language specialist's perspective: interviews with krashen, omaggio hadley, terrell, and rardin," Foreign Language Annals, vol. 25, no. 2, pp. 157-172, 1992.

[20] F. S. Steinberg and E. K. Horwitz, "The effect of induced anxiety on the denotative and interpretive content of second language speech,” Tesol Quarterly, vol. 20, no. 1, pp. 131-136, 1986.

[21] R. C. Gardner and P. D. MacIntyre, "On the measurement of affective variables in second language learning," Language Learning, vol. 43, no. 2, pp. 157-194, 1993.

[22] P. Burden, "The teacher as facilitator: reducing anxiety in the EFL university classroom," JALT Hokkaido Journal, vol. 8, pp. 3-18, 2004.

[23] P. D. MacIntyre and R. C. Gardner, "Methods and results in the study of anxiety and language learning: a review of the literature *," Language Learning, vol. 41, no. 1, pp. 85-117, 1991.

[24] S. Boun, "Social psychological impacts on language use: anxiety among Cambodian university students," TESOL International Journal, vol. 12, no. 2, pp. 16-31, 2017.

[25] R. Ellis, The Study of Second Language Acquisition, Oxford University Press, Oxford, UK, 1994.

[26] Y.-C. Sun and F.-Y. Yang, "I help, therefore, I learn: service learning on Web 2.0 in an EFL speaking class," Computer Assisted Language Learning, vol. 28, no. 3, pp. 202-219, 2015.

[27] S. Zhang, "The role of input, interaction and output in the development of oral fluency," English Language Teaching, vol. 2, no. 4, pp. 91-100, 2009.

[28] T. Oya, E. Manalo, and J. Greenwood, "The influence of personality and anxiety on the oral performance of Japanese speakers of English," Applied Cognitive Psychology, vol. 18, no. 7, pp. 841-855, 2004.

[29] E. Phillips, "Decreasing language anxiety: practical techniques for oral activities," in Affect in Foreign Language and Second Language Learning: A Practical Guide to Creating a Low Anxiety Classroom Atmosphere, D. Young, Ed., McGraw-Hill, New York, NY, USA, 1999.

[30] B. Mak, "An exploration of speaking-in-class anxiety with Chinese ESL learners," System, vol. 39, no. 2, pp. 202-214, 2011.

[31] M. Liu and J. Jackson, "An exploration of Chinese EFL learners' unwillingness to communicate and foreign language anxiety," The Modern Language Journal, vol. 92, no. 1, pp. 71-86, 2008.

[32] C. Gkonou, "A diary study on the causes of English language classroom anxiety," International Journal of English Studies, vol. 13, no. 1, pp. 51-68, 2013.

[33] J. S. Boyce, S. R. Alber-Morgan, and J. G. Riley, "Fearless public speaking," Childhood Education, vol. 83, no. 3, pp. 142-150, 2007.

[34] G. Subasi, "What are the main sources of Turkish EFL students' anxiety in oral practice?" Turkish Online Journal of Qualitative Inquiry, vol. 1, no. 2, pp. 29-49, 2010.
[35] R. J. Croft, C. J. Gonsalvez, J. Gander, L. Lechem, and R. J. Barry, "Differential relations between heart rate and skin conductance, and public speaking anxiety," Journal of Behavior Therapy and Experimental Psychiatry, vol. 35, no. 3, pp. 259-271, 2004.

[36] R. G. Heimberg, D. A. Hope, C. S. Dodge, and R. E. Becker, "DSM-III-R subtypes of social phobia," The Journal of Nervous and Mental Disease, vol. 178, no. 3, pp. 172-179, 1990.

[37] D.-P. Pertaub, M. Slater, and C. Barker, "An experiment on public speaking anxiety in response to three different types of virtual audience," Presence: Teleoperators and Virtual Environments, vol. 11, no. 1, pp. 68-78, 2002.

[38] J. M. Lee, J. H. Ku, D. P. Jang et al., "Virtual reality system for treatment of the fear of public speaking using image-based rendering and moving pictures," CyberPsychology and Behavior, vol. 5, no. 3, pp. 191-195, 2002.

[39] I. Bernátová, P. Bališ, R. Goga, M. Behuliak, J. Zicha, and I. Sekaj, "Lack of reactive oxygen species deteriorates blood pressure regulation in acute stress," Physiological Research, vol. 65, no. 3, pp. S381-S390, 2016.

[40] A. Vîslă, I. Cristea, A. Tătar, and D. David, "Core beliefs, automatic thoughts and response expectancies in predicting public speaking anxiety," Personality and Individual Differences, vol. 55, no. 7, pp. 856-859, 2013.

[41] B. Gorjian, S. R. Moosavinia, K. Ebrahimi Kavari, P. Asgari, and A. Hydarei, "The impact of asynchronous computerassisted language learning approaches on English as a foreign language high and low achievers' vocabulary retention and recall," Computer Assisted Language Learning, vol. 24, no. 5, pp. 383-391, 2011.

[42] D. McQuail, McQuail's Mass Communication Theory, SAGE Publications, Newcastle Upon Tyne, UK, 2005.

[43] H. M. Satar and N. Özdener, "The effects of synchronous CMC on speaking proficiency and anxiety: text versus voice chat," The Modern Language Journal, vol. 92, no. 4, pp. 595-613, 2008.

[44] N. Arnold, "Reducing foreign language communication apprehension with computer-mediated communication: a preliminary study," System, vol. 35, no. 4, pp. 469-486, 2007.

[45] H.-Y. Hsu, S.-K. Wang, and L. Comac, "Using audioblogs to assist English-language learning: an investigation into student perception," Computer Assisted Language Learning, vol. 21, no. 2, pp. 181-198, 2008.

[46] Y. Sun, "Voice blog: an exploratory study of language learning," Language, Learning and Technology, vol. 13, no. 2, pp. 88-103, 2009.

[47] A. K. Wehner, A. W. Gump, and S. Downey, "The effects of Second Life on the motivation of undergraduate students learning a foreign language," Computer Assisted Language Learning, vol. 24, no. 3, pp. 277-289, 2011.

[48] F. Wang and E. Shao, "Using Second Life to assist EFL teaching: we do not have to sign in to the program," TechTrends, vol. 56, no. 4, pp. 15-18, 2012.

[49] C. Balcikanli, "Language learning in Second Life: American and Turkish students' experiences," The Turkish Online Journal of Distance Education, vol. 13, no. 2, pp. 131-146, 2012.

[50] H.-C. Liou, "The roles of Second Life in a college computerassisted language learning (CALL) course in Taiwan, ROC," Computer Assisted Language Learning, vol. 25, no. 4, pp. 365-382, 2012.

[51] M. Bashori, R. van Hout, H. Strik, and C. Cucchiarini, "Webbased language learning and speaking anxiety," Computer Assisted Language Learning, pp. 1-32, 2020. 
[52] J. York, K. Shibata, H. Tokutake, and H. Nakayama, "Effect of SCMC on foreign language anxiety and learning experience: a comparison of voice, video, and VR-based oral interaction," ReCALL, vol. 33, no. 1, pp. 1-22, 2021.

[53] N. V. Ivankova, J. W. Creswell, and S. L. Stick, "Using mixedmethods sequential explanatory design: from theory to practice," Field Methods, vol. 18, no. 1, pp. 3-20, 2006.

[54] K. Yaikhong and S. Usaha, "A measure of EFL public speaking class anxiety: scale development and preliminary validation and reliability," English Language Teaching, vol. 5, no. 12, pp. 23-35, 2012.

[55] M. Craven and K. D. Sherman, Q: Skills for Success Special Edition Listening and Speaking Level 3, Oxford University Press, Oxford, UK, 2nd edition, 2020.

[56] J. C. McCroskey, "Measures of communication-bound anxiety," Speech Monographs, vol. 37, no. 4, pp. 269-277, 1970.

[57] T. Clevenger and S. K. Halvorson, Converting the PRCA-State Version 2 to the Speech Anxiety Scale, The Florida State University, Tallahassee, Fl, USA, 1992.

[58] K. Krippendorff, Content Analysis: An Introduction to its Methodology, SAGE, Newcastle Upon Tyne, UK, 2004.

[59] J. Swan, "Using cognitive mapping in management research: decisions about technical innovation," British Journal of Management, vol. 8, no. 2, pp. 183-198, 1997.

[60] L. Plonsky and F. L. Oswald, "How big is "big"? Interpreting effect sizes in L2 research," Language Learning, vol. 64, no. 4, pp. 878-912, 2014.

[61] R. Hampel and U. Stickler, "The use of videoconferencing to support multimodal interaction in an online language classroom," ReCALL, vol. 24, no. 2, pp. 116-137, 2012. 